\title{
Impact of Financial Status on Consanguineous Marriages in Muslim Population of Kurnool Town
}

\author{
Dr. S. Shamshad ${ }^{1}$, S. Shameela ${ }^{2}$, A. Indira Priyadarsini ${ }^{3}$ \\ ${ }^{1}$ Department of Zoology, K.V.R. Govt. College for Women, Kurnool, A.P., India \\ ${ }^{2}$ Department of Biochemistry, S.K. University, Anantapur, A.P., India
}

${ }^{3}$ Department of Botany, S.V.A Govt. Degree College for Men, Srikalahasti, A.P., India

\begin{abstract}
Consanguinity refers to intra-familial marriage and is commonly used to refer cousin marriage. Consanguineous marriages are frequent in many populations in India. The study was conducted on 1050 Muslim families to investigate the impact of financial status on frequency of consanguineous marriages. The result from this study reveals that, in LIG, the prevalence of abortions, IUDs, PMBs, NTDs, MRs and CHDs are higher in consanguineous mothers than non consanguineous mothers. No/Less cases were found among MIG and HIG. This study clearly indicates that the financial status plays an important role.
\end{abstract}

Keywords: Consanguinity, LIG, MIG, HIG, abortions

\section{Introduction}

Consanguineous marriage is a traditional practice in many communities around the world. It is defined as a marriage between two people who are second cousins or more closely related [1]. The most common prevailing form of consanguineous marriage is between first cousins [2]. However, consanguineous marriage range from cross cousin to more distant relations and their prevalence varies by cultural traditions followed by a community [3], [4]. Onefifth of the human population around the world lives in communities with a preference for consanguineous marriage and at least $8.5 \%$ of children have consanguineous parents [5]. The prevalence of preference for consanguineous unions is particularly high in South Asian population [6], [7]. In Indian context, Hussain and Bittles analysed the National Family Health Survey (1992-93) and found the prevalence of consanguineous marriage is around $12 \%$ but, among Muslims, it is 22\% [8]. Blood related marriages have higher prevalence in Southern states of India [9]. The distribution of preference for consanguineous marriage thereby demonstrating that four south Indian states including Andhra Pradesh, Karnataka, Kerala, and Tamil Nadu, follow a widespread practice of consanguineous marriage in all their administrative districts [6]. This social custom is practiced mainly for religious and economic reasons [10].

In general, consanguinity is influenced by geographic, demographic, religious, cultural, and socio-economic factors [11] - [13]. The highest rates of consanguineous unions were associated with low socio-economic status, low education, and living in rural areas [14] - [18]. Previous literature tells us that, women married to their blood relatives experienced a greater amount of pregnancy wastage and child loss as compared to those women married to their distant relatives or nonrelatives. Children from consanguineous marriages are at a greater risk of inheriting harmful condition caused by homozygous recessive genes and consequently suffer autosomal recessive genetic disorders [19], [20]. The prevalence of still births and birth defects is substantially greater in the offspring of first cousin parents [21]. Moreover, studies also reveal that the risk of congenital heart diseases is considerably higher among children with parental consanguinity than non-consanguinity [22]. A study by Kulkarni \& Kurian found a significantly higher rate of stillbirths, congenital malformations, low birth weight and head circumference among children born within consanguineous marriage compared to non-consanguineous marriage [23]. The present investigation meets the critical need to update the knowledge and information on consanguineous marriages and its effects on pregnancy outcomes by economic groups across Kurnool town. In addition, it quantifies consanguineous marriages effect on adverse pregnancy outcomes across economic groups.

\section{Materials and Methods}

A convenience sample of 1050 married women between the ages of 15-49 was personally interviewed using a structured questionnaire in Kurnool town to determine the prevalence of consanguineous marriages. A family pedigree was drawn for each marriage to record the type of consanguineous relationship involved. The specific questions asked in this survey are - Are you related to your husband by blood? If so, what is the relationship?" (Options given for this question are no relation, Cousin, Others). Similarly, questions were asked to women concerning the economic status (Low Income Group (LIG), Middle Income Group (MIG), High Income Group (HIG) and the history of pregnancy outcomes such as stillbirth, miscarriage, spontaneous abortion and induced abortion, [24]. The data obtained was fed into the computer and compared and contrasted with the rate of consanguineous and non-consanguineous marriages with respect to financial status.

\section{Results and Discussion}

India is a heterogeneous state with diverse cultures and traditional practices in the different regions. Studies in a global context have also identified factors effecting consanguineous marriages. Akrami and Osati aptly pointed out that social and cultural factor responsible for 


\section{International Journal of Science and Research (IJSR) \\ ISSN (Online): 2319-7064 \\ Index Copernicus Value (2013): 6.14 | Impact Factor (2014): 5.611}

consanguineous marriages, particularly among Muslims [25]. A majority of the literature on consanguinity in India focuses primarily on the southern states. However, this study presented a comparative assessment representative of three income groups in muslim population of Kurnool town of Andhra Pradesh state. Table 1 shows the income wise prevalence of disorders in consanguineous and non consanguineous marriages. For this study, total of 1050 Muslim women were interviewed, of which $72.48 \%$ were LIG, $17.90 \%$ were MIG, and 9.62\% were HIG.

Consanguineous marriage has been repeatedly found to have an association with birth defects [26], [27].Overall, the results reveal that the prevalence of abortions is greater among women of MIG who got married to their blood relatives (26.4\%) compared to the women who got married to distant relatives (7.7\%). However consanguineous parents of LIG show a greater abortion rate $(16 \%)$ than non consanguineous parents (4\%) of the same income group. Also 6.8\% abortions were seen in the non consanguineous parents of HIG, indicates that not only the consanguinity, but also some other factors may responsible for their abortions.

Analogous to the results of abortions, the results for occurrence of IUDS also showed greater prevalence among women who had consanguineous marriages (9\%) compared to non-consanguineous marriages (1.1\%). But surprisingly the prevalence of IUDS reported among women who had non consanguineous marriages of MIG (1.94\%) and HIG (5.74\%) and nil IUDS were reported among women who had consanguineous marriages of the same groups.

Table 1: Anomalies in different income groups

\begin{tabular}{|c|c|c|c|c|c|c|}
\hline \multirow{4}{*}{ Anomalies } & \multicolumn{2}{|c|}{ LIG } & \multicolumn{2}{c|}{ MIG } & \multicolumn{2}{c|}{ HIG } \\
\cline { 2 - 7 } & $\begin{array}{c}\text { CM } \\
(130)\end{array}$ & $\begin{array}{c}\text { Non } \\
\text { CM } \\
(631)\end{array}$ & $\begin{array}{c}\text { CM } \\
(34)\end{array}$ & $\begin{array}{c}\text { Non } \\
\text { CM } \\
(154)\end{array}$ & $\begin{array}{c}\text { CM } \\
(14)\end{array}$ & $\begin{array}{c}\text { Non CM } \\
(87)\end{array}$ \\
\hline Abortions (\%) & 16 & 04 & 26.4 & 7.7 & - & 6.8 \\
\hline IUD (\%) & 9 & 1.1 & - & 1.94 & - & 5.74 \\
\hline CHD (\%) & 11.5 & 1.58 & 8.8 & - & - & - \\
\hline NND (\%) & 25.3 & 4.75 & 5.8 & - & 7.1 & 1.1 \\
\hline PMB (\%) & 7.6 & 0.9 & 20.58 & 4.54 & 14.2 & 6.8 \\
\hline
\end{tabular}

*CM consanguineous marriage * IUD intra uterine death *CHD congenital heart disease *NND neo natal deaths * PMB pre mature birth.

Income relates directly to the material conditions that influence health, such as living condition, medical care, and lifestyle [28]. The results from this study reveal that, with reference to economic status, the prevalence of CHDS is decreased with increasing income level in consanguineous parents. The rate of CHD is more in consanguineous parents of LIG (11.5\%) and MIG (8.8\%) compared to nonconsanguineous of LIG (1.58 \%) and MIG (0 \%) . our data did not show any notable CHDs in consanguineous and nonconsanguineous parents of HIG.

As expected, our study showed that, the higher prevalence of NNDs were observed in consanguineous parents (25.3\%) compared to the non consanguineous parents (4.75\%) of LIG. we also observed the prevalence of NNDs were high in consanguineous parents $(7.1 \%)$ compared to the non consanguineous parents (1.1\%) of HIG. In MIG we observed
NNDs only in the consanguineous parents (5.8\%) but not in the non consanguineous parents.

The rate of PMB is not associated with economic status, but there was a positive correlation between consanguinity and pre mature birth. PMBs are more in the consanguineous marriages of every income group compared to non consanguineous marriages.

\section{Conclusion}

The current study found the greatest risk of examined birth defect phenotypes in association with the lowest household economic status and rough gradient associations of household index with abortions, IUDs, CHDs, NNDs and PMBs. Lower economic status is often considered to be a marker for other factors in the pathway to worse health outcomes.

\section{Acknowledgements}

I am very much grateful to UGC for funding the project under minor research project scheme MRP-4812/14(SERO/UGC).

\section{References}

[1] World Health organization. Report of a WHO Advisory Group on Hereditary Diseases. Document HMG/WG/85. 8a, Geneva. 1985.

[2] M. Al-Salem, \& N. Raishdeh. Consanguinity in north Jordan: Prevalence and pattern", Journal of Biosocial Science, 25(4), 553-556. 1993.

[3] A.H. Bittles, S.A. Shami, \& N. Appaji Rao. Consanguineous in southern Asia: Incidence causes and effects, In Minority Populations: Genetics, Demography and Health (eds. Bittles, A. H. and Roberts, D. F.) (Pp 102-118) Macmillan Press, London. 1992.

[4] K. Yunis, R. El Rafei \& G. Mumtaz. Consanguinity: Perinatal outcomes and prevention-a view from the Middle East", NeoReviews, 9(2), e59. 2008.

[5] B. Modell \& A. Darr. Science and society: Genetic counselling and customary consanguineous", Nature Reviews Genetics, 3, 225-229. 2002.

[6] B.E.F. Beck, Peasant Society in Konku. University of British Columbia Press, Vancouver. 1972.

[7] R. Chakraborty \& A. Chakravarti. - On consanguineous marriages and the genetic load", Human Genetics, 36, 47-54. 1977.

[8] R. Hussain \& A.H. Bittles, Sociodemographic correlates of consanguineous marriage in the Muslim population of India", Journal of Biosocial Science. 32(4), 433-442. 2000.

[9] A.H. Bittles A. Radha Rama Devi, H.S. Savithri, Rajeshwari Sridhar, N. Appaji Rao. Inbreeding and post-natal mortality in South India: Effects on the gene pool. J Genet. 64:135-142. 1985.

[10] A.H. Bittles. The role and significance of consanguinity as a demographic variable. Popul Dev Rev. 561- 584. 1994.

[11] A.H. Bittles. Consanguinity and its relevance to clinical genetics. Clin Genet. 60:89-98. 2001. 
[12] R. Hussain. Community perceptions of reasons for preference for consanguineous marriages in Pakistan. $\mathrm{J}$ Biosoc Sci. 31:449-61. 1999.

[13] M. Saadat. Consanguineous marriages in Iranian folktales. Community Genet. 10:38-40. 2007.

[14] A. Bener, R. Hussain. Consanguineous unions and child health in the State of Qatar. Paediatr Perinat Epidemiol. 20:372-8. 2006.

[15] S. Zaoui, C. Biemont. Frequency of consanguineous unions in the Tlemcen area [in French]. Cahiers d'etudes et de recherches francophones/Sante. 12:289295. 2002.

[16] S. Simsek, M. Ture, B. Tugrul, N. Mercan, H. Ture, B. Akdag. Consanguineous marriages in Denizli, Turkey. Ann Hum Biol. 26:489-91.1999.

[17] R. Liascovich, M. Rittler, E.E. Castilla. Consanguinity in South America: demographic aspects. Hum Hered. 51:27-34. 2001

[18] R. Jurdi, P.C. Saxena. The prevalence and correlates of consanguineous marriages in Yemen: similarities and contrasts with other Arab countries. J Biosoc Sci. 35:113. 2003

[19] P.V. AshaBai, \& T. Jacob John. The effect of consanguinity on the gestation period and anthropometric traits of the new-born in Southern India", Tropical Geography and Medicine, 34, 225-229. 1982

[20] S. Sureender, B. Prabakaran, \& A.G. Khan. Mate selection and its impact on female age, pregnancy wastages, and first child survival in Tamil Nadu, India", Social Biology, 45, 289-301. 1998.

[21] C. Stoll, Y. Alembik, B. Dott, B. \& J. Feingold. Parental consanguinity as a cause of increased incidence of birth defects in a study of 131,760 consecutive births", American journal of medical genetics, 49 (1), 114-117. 1994

[22] R.S. Gowda, \& N.B. Ramachandra. Parental consanguinity increases congenital heart diseases in South India", Annals of human biology. 33 (5-6), 519528. 2006

[23] M.L. Kulkarni \& M. Kurian, Consanguinity and its effect on fetal growth and development: a south Indian study", Journal of Medical Genetics. 27(6), 348-352. 1990

[24] S. Desai, A. Dubey, B.L. Joshi, M. Sen, A. Shariff and R. Vanneman. India Human Development Survey: Design and Data Quality. University of Maryland, College Park, MD. 2005

[25] S.M. Akrami, Z. Osati †s consanguineous marriage religiously encouraged? Islamic and Iranian considerations", Journal of Biosocial Science, 39, 313316. 2007

[26] M. Rittler, R. Liascovich, J. López-Camelo, E.E. Castilla: Parental consanguinity in specific types of congenital anomalies. Am J Med Genet. 102 (1): 36-43. 2001

[27] S.M. Becker, Z. Al Halees ,C. Molina, R.M.Paterson: Consanguinity and congenital heart disease in Saudi Arabia. Am J Med Genet. 99 (1): 8-13. 2001.

[28] J. Lynch, G. Kaplan. Socioeconomic position. In: Berkman LF, Kawachi I, editors. Social epidemiology. New York, NY: Oxford University Press; p. 13-35. 2003. 